\title{
Prix du 3 juillet 1608
}

La revue médecine/ sciences s'est vu attribuer le "prix du 3 juillet 1608 ". Ce prix que décerne le Conseil de la Langue française du Québec a été créé par le Gouvernement du Québec pour commémorer la date de fondation de Québec, premier établissement français en Amérique du Nord. Il est décerné annuellement à une association ou à un établissement pour services exceptionnels rendus à l'ensemble de la francophonie nord-américaine. La ministre de la Culture et des Communications du Québec, Madame Louise Beaudouin, a présenté aux rédacteurs en chef $\mathrm{Mi}$ chel Bergeron (Montréal) et Axel Kahn (Paris), une médaille ainsi qu'une œuvre d'art, un diptyque réalisé par l'artiste-graveur québécois, M. René Derouin et intitulé Ies territoires.

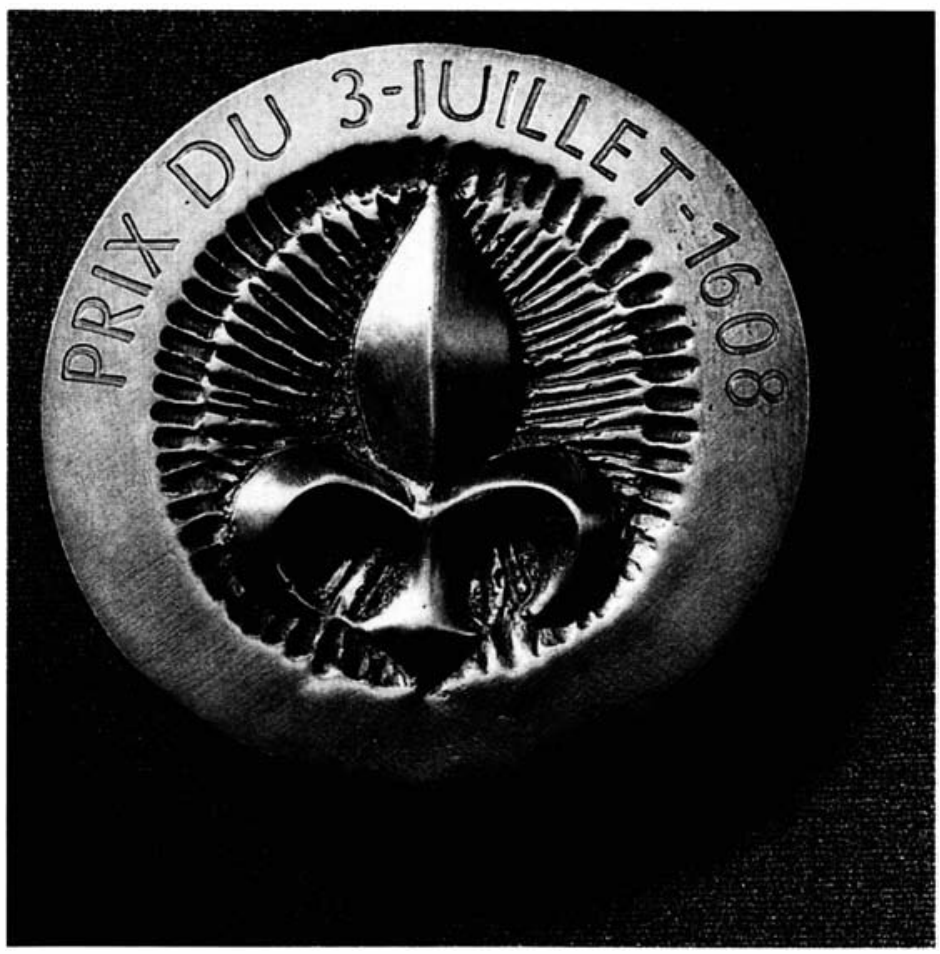

té, la nôtre, qui a reconnu l'importance de s'approprier la science, le langage étant la première forme d'appropriation. $\mathrm{Mme}$ Beaudouin a également souligné le rôle que joue médecine/ sciences comme grande revue de langue française et généraliste des sciences biologiques et médicales.

A cette même occasion, Monsieur Marcel Masse, président du Conseil de la Langue française et Madame la Ministre Beaudouin ont également remis les insignes de l'Ordre des francophones d'Amérique à douze personnalités venant du Québec, de l'Acadie, de l'Ontario, de l'Ouest

Madame la Ministre Beaudouin a rappelé devant les quelque 400 persomnes réunies au Parlement du Québec que médecine/sciences est un symbole de réussite pour une socié- canadien et des Etats-Unis ainsi qu'à Madame Margie Sudre, secrétaire d'État chargée de la francophonie au sein du Gouvernement français. 